\title{
PROFUTURO, A SOCIAL INITIATIVE TO IMPROVE EDUCATION WITH E-LEARNING ANALYTICAL TOOLS
}

\author{
Vidal Alonso Secades, Olga Arranz-García and Alfonso Jose López Rivero \\ Universidad Pontificia de Salamanca \\ C/Compañia, 5, 37002, Salamanca, Spain
}

\begin{abstract}
One of the main factors that governments and enterprises have to bridge the digital gap in society is Education. Profuturo is a foundation that develops a proposal on digital education in order to reduce that gap in vulnerable areas working with e-learning programs. These e-learning activities bring them a large data set that can be analyzed with learning analytics tools, such as big data or artificial intelligence technology. The use of these technologies has the aim to improve the learning process in those vulnerable areas and to act in a personal way such as the students have been demanded. This short paper shows how the data analysis obtained from mathematics and linguistic data can be used in order to identify talented students in those areas.
\end{abstract}

KEYWORDS

e-Learning, Online Education, Profuturo Foundation, Artificial Intelligence, Big Data

\section{INTRODUCTION}

The development of a society has in education one of the main factors of wellbeing and progress in order to satisfy their citizens. This makes that most of the leaders and business entities have always education as an area for improvement, in order to provide a quality educational training to look to the future with hope. (U.S. Department of Education, 2012).

UNESCO, as the Organization of the United Nations responsible for the education, has focused, on two of its last working papers, in the reorientation of the use made of the stored data in information systems to a more equitable and inclusive process that promotes a quality education (UNESCO, 2018) and to the use of artificial intelligence as an item of information processing that allows for a more sustainable educational development (UNESCO, 2019).

This short paper aims to show, in this context, the initiative implemented by Profuturo Foundation to improve education in vulnerable areas, (Guatemala, Peru, Angola, Philippines, Colombia, Belize, Brazil,...), through e-learning processes. The initiative is in a continuous improvement process fed by a data analysis with technological tools based on Big data analytics or artificial intelligence, that is currently being executed in collaboration with the Computer Science Faculty of the Pontifical University of Salamanca. So, the paper makes a brief introduction to the project of the Profuturo Foundation, addresses the relationship between technology and the analytical e-learning processes and displays a case study analyzed from the data collected.

\section{PROFUTURO FOUNDATION}

Profuturo is a digital educational proposal launched by Telefonica Foundation and "La Caixa" Foundation, whose mission is to reduce the educational gap, providing a quality digital education to boys and girls who are in vulnerable environments in Africa, Latin America and Asia. This proposal involves the main educational agents such as school principals, teachers, students and families, and seeks to promote agreements with governments and relevant educational institutions of each country, to work in conjunction with the official plans. (Profuturo, 2019) 
Its objective is to prevent that the digital gap in education joined with the existing gap of the socioeconomic environment of these areas and offer an inclusive, equitable and quality digital education, to achieve equal opportunities. To achieve this goal it uses the digital technology as a way of affordable and effective access to quality education, where geographical barriers are removed and the scalability will be favored. Through this digital technology is facing three educational challenges:

1) New learning models: Going from a student-centered learning in a model of project based learning.

2) New skills: Creativity, critical spirit, innovation or learning to learn.

3) New teacher role: Proactive, guide, coach.

The pedagogical model is a blended learning model, customized, modular, flexible and coordinated with the local entities. This model can be deployed to any vulnerable environment, with or without connectivity, as it adapts to the circumstances of each area or country, even in schools without equipment or connectivity. The model focuses on the skills development linked with linguistics and the STEAM (Science, Technology, Arts and Mathematics) area, as well as it develops common digital skills, communication skills, teamwork, creativity, problem solving, or decision-making process.

The key to the program is the teacher training. ProFuturo train them in the use of digital tools to develop personalized learning resources, helps them to improve their digital competence and encourages collaborative work for creating a large international network of education centers that teach, learn and share knowledge, fostering the creation of their own content.

In order to assess the effectiveness of this method and its subsequent adaptation and replication in other educational centers, Profuturo sets a set of analytical processes to measure and evaluate the impacts of continuous improvement. These analytical processes are being implemented with learning analytics tools based on algorithms and big data for assessing the results and the impact of the quality and transformation of education. We must highlight, as an example, the application "Teacher Assistant" that through e-learning analytics allows you to detect, daily, if a child is falling behind and put measures in their recovery, as well as offer more challenges to the more advanced students.

\section{ELEARNING \& TECHNOLOGICAL TOOLS}

The data collection and the data storage obtained from the different activities of e-learning, engaged in a learning management platform, enables subsequent treatment through technological tools. Big data, learning analytics, artificial intelligence, are some of the current trends that are extracting new knowledge in education area and are being used to improve student's education. (Hamoud et al., 2018) (Leading Countries of the World, 2018)

The application of Big Data to the education area has allowed a greater customization of the teaching methods and has brought a greater feedback to students (Daniel, 2014; Avella et al., 2016). This feedback increases the student's motivation with respect to the current teaching-learning process, as they work with new teaching and learning methods through mobile apps or the combined learning process.

Regarding the term of Learning Analytics, Ferguson et al. (2016) defines it as "the measure, data collection, analysis and reporting on students and their contexts, in order to understand and optimize learning and the environments in which takes place". This definition allows us to extrapolate the importance that techniques and processing procedures used in learning analytics can reach, for the educational area, when it comes to understand and optimize the learning processes (Lee et al., 2019). This optimization should be developed in a process of four phases for success:

1. Set goals and metrics: It is important to establish, at the beginning of the process, which is the goal to be achieved and the metrics that will be used in order to verify the achievement of the goal.

2. Data Collection: The main source of analysis will be the data collected and cleaned from the activities developed by the students in the e-learning platform.

3. Analyze and visualize information: The analysis with technological tools, adapted to the established objectives, allow us to view the new knowledge obtained.

4. Act: The application of this knowledge will modify the activities of the e-learning process in order to improve student's marks. 
Also, the artificial intelligence is emerging as the technology of the future to predict or discover knowledge in educational data sets. Processes such as Machine learning or Deep learning processes can discover patterns of behavior, based on the student's actions, in order to improve the e-learning process (Tuomi, 2018). This trend was reaffirmed in the Mobile Learning Week (2019) where it was agreed, at the European Union and the UNESCO member countries, to establish policies to encourage the development of educational data analytics with artificial intelligence techniques, and, also, to train teachers in an education oriented to artificial intelligence. (UNESCO, 2019).

\section{A STUDY CASE}

This paper displays a study case which is interested in the identification of talented students in the respective vulnerable areas where the program is implemented. In order to verify the achievement of this aim, the study case will collect, as a metric of success, the percentiles of each student in the courses they have been completed. We shall estimate that a percentile greater than or equal to 90 will be considered as a successful event.

\subsection{Data Collection \& Data Cleansing}

The data collection process starts with the recollection and storage of data from the vulnerable areas, using the platform e-learning activities. The number of participants varies from one area to another, but at least we collect more than 5000 records from each area. In order to obtain some useful information, we shall consider a data collection just for 2 subjects: Linguistics and Mathematics. For the linguistic subject we shall take data from activities that affect vowels, verbs, nouns, prayers, gender and adjectives, while for the mathematics subject we shall discuss activities that encompass volumes, measurement, addition, subtraction, geometry and numbering systems.

These data should be treated using technological tools of filtering, removing and cleaning, which allow us to retrieve data in a format that can be applied to the relevant analysis. In this study case, as a filter activity and to provide students with a meaningful activity, we shall only be regarded as students who have completed more than 10 activities. In the same way, and as a removing activity, we shall remove the inconsistent data detected.

Finally, data cleansing will be transforming the raw data in tidy data. For example, the cleaning process transforms all the characters in lower case, or updates the data noise, such as, those activities that have a mark bigger than 100 points.

\subsection{Data Analysis \& Data Visualization}

Once you have preprocessed the data collected, you will continue the study case with a quality data set. So, it is time to start the learning analytics process, directing this analysis to the achievement of the goal set, i.e. the identification of talent.

In this analysis, it is used, both for the treatment of data as well as for exploratory analysis, the language R, where through the tool RStudio is implementing the corresponding code that allows you to analyze the undertaken platform activities and their results.

The analysis is made by the combination of several factors, such as the activity identifier, the identification of the student, the date of implementation, the type of activity, the number of students per course, the zone identifier, the materials used or the teachers involved.

The data visualization phase has been implemented with TIBCO Spotfire, which is a tool that builds graphics to display the results of the processed data, obtaining curious results. For example, Figure 1 represents data visualization for the linguistics subject, where the horizontal axis represents the students registered and the vertical one represents the mark obtained. It is possible to extrapolate from the Figure 1, that the fewer students to attend the course (between 10 and 15), worst are the results of the learning process. This association allows us to interpret a possible association between students' motivation regarding contents and the number of students that are enrolled in each course. 


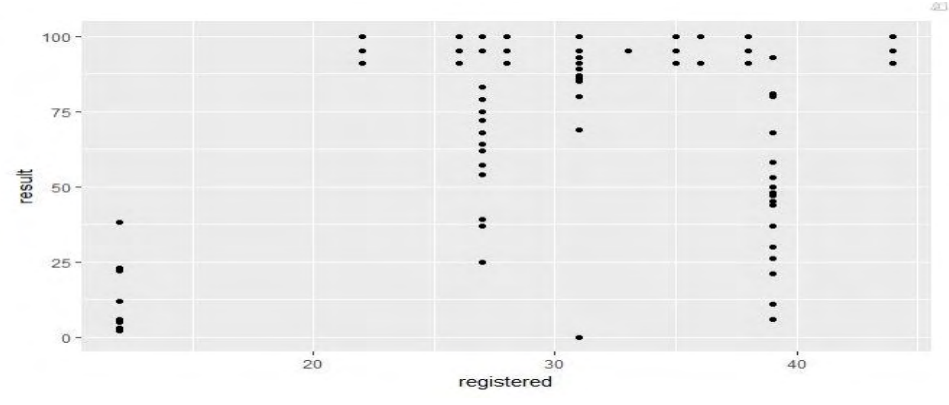

Figure 1. Marks / Enrolled Students

Considering this extrapolation we shall act, in the future, to enroll between 20 and 35 students in each course in order to improve student's marks and their motivation.

Furthermore, we also obtained, in the Table 1 below, the data analytics relating to the results achieved in the e-learning activities of linguistics and mathematics. We used this table to observe the objective of the study case, and, so, we proceed to their classification with reference to the percentiles.

Table 1. Results of the analysis of activities of linguistics and mathematics

\begin{tabular}{lcc}
\hline Percentiles & Linguistics Percent & Mathematics Percent \\
\hline Greater than or equal to 90 & $\mathbf{7 9 , 3} \%$ & $\mathbf{8 4 , 0} \%$ \\
Between 1 and 89 & $\mathbf{1 6 , 1} \%$ & $\mathbf{8 , 3} \%$ \\
Equal to 0 & $\mathbf{4 , 6 \%}$ & $\mathbf{7 , 7} \%$ \\
\hline
\end{tabular}

The analysis of this table allows us to observe the presence of a greater talent in the field of mathematics (84\%) than in the field of linguistics $(79,3 \%)$, and a total failure lower in linguistic activities $(4,6 \%)$ than in mathematics $(7,7 \%)$. So, we will have more opportunities to find more talent in the students who have completed mathematics than in the students who have completed linguistics.

\section{CONCLUSION}

As we have observed, the commitment of Profuturo Foundation with evolution educative in vulnerable environments is a confirmed fact. This compromise encompasses not only the physical layout of equipment and connection, but also the analysis of e-learning activities carried out by students, in order to enhance the teaching/learning process.

This analysis, carried out with the latest technological trends, such as Big Data and Artificial Intelligence tools, feed the learning process to establish new and innovative activities that increase student motivation with respect to the training subject.

This optimization would be improved with the automation of the tedious work of data cleansing, as well as the thinning of the algorithms that are used in the e-learning analytical activities, implemented with artificial intelligence techniques or with big data technology.

As we have seen in the case study, it is possible to collect records from the student's activities in the e-learning platform and process them with the analytical tools in order to identify who are the students with more talent, and what are the factors (number of students) that could improve e-learning education activities.

There is still too much work to realize in these vulnerable areas, but this proposal could be the first step to bring education closer to children and offer a better future. 


\section{REFERENCES}

Avella, J., et al., 2016. Learning Analytics Methods, Benefits, and Challenges in Higher Education: A Systematic Literature Review. In Online Learning, Vol. 20, No. 2, pp 13-29

Daniel, B., 2014. Big Data and analytics in higher education: Opportunities and challenges. In British Journal of Educational Technology, doi: 10.1111/bjet.12230

Ferguson, R., et al, 2016. Research Evidence on the Use of Learning Analytics - Implications for Education Policy. Joint Research Centre Science for Policy Report; EUR 28294 EN; doi: 10.2791/955210

Hamoud, A., et al., 2018. Predicting Student Performance in Higher Education Institutions Using Decision Tree Analysis. In International Journal of Interactive and artificial intelligence, Vol. 5, No. 2, pp 26-31.

Leading Countries of the World, 2018. Lessons from Using Advanced Learning Analysis in Education Sector. Available at:https://www.leadingcountries.com/wpcontent/uploads/2018/08/19498_MSEdu_LearningAnalytics12ppBrochure_V2.pdf

Lee, J., et al., 2019. Exploring Factors and Indicators for Measuring Students'Sustainable Engagement in e-Learning. In Sustainability, Vol. 11, No. 4, https://doi.org/10.3390/su11040985

Mobile Learning Week, 2019. https://en.unesco.org/mlw

Profuturo, 2019. https://www.fundaciontelefonica.com/educacion innovacion/profuturo/

Tuomi,I., 2018 The Impact of Artificial Intelligence on Learning, Teaching, and Education. Policies for the future, Eds. Cabrera, M., Vooraki, R. \& Punie, Y., EUR 29442 EN, Publications Office of the European Union, Luxembourg, doi: 10.2760/12297, JCR113226

UNESCO, 2018. Re-orienting Education Management Information Systems towards Inclusive and Equitable Quality Education and Lifelong Learning. UNESCO Working Papers on Education, No. 5.

UNESCO, 2019. Artificial Intelligence in Education: Challenges and Opportunities for Sustainable Development. UNESCO Working Papers on Education, No. 7.

U.S. Department of Education, Office of Educational Technology, 2012. Enhancing Teaching and Learning Through Educational Data Mining and Learning Analytics: An Issue Brief. Washington, D.C 